\title{
Innovative materials for fusion power plant structures: separating functions
}

\author{
A M Stoneham ${ }^{1}$, J R Matthews and I J Ford \\ Centre for Materials Research, Department of Physics and Astronomy, University College \\ London, Gower Street, London WC1E 6BT, UK \\ E-mail: a.stoneham@ucl.ac.uk
}

Received 19 November 2003

Published 25 June 2004

Online at stacks.iop.org/JPhysCM/16/S2597

doi:10.1088/0953-8984/16/27/001

\begin{abstract}
Fusion reactors create extreme conditions for structures close to the plasma. It seems unlikely that materials currently being considered can meet all performance requirements under such conditions. We explore the possibility of separating functionality in composite structures to overcome this barrier. To this end, several suggestions of directions are made for the search for such materials. In particular, we note some of the new materials that have become available only in the last two decades. Those discussed include the use of diamondlike carbon coatings, nano-structured materials, layered structures, stacked structures, and viscous coatings, including more complex carbon composite materials. Materials modelling will be an important component in the search for viable materials. However, the extreme conditions and the nature of the radiation damage demand extensions both to molecular dynamics and to the much-used Norgett-Robinson-Torrens model. We identify some of the relevant condensed matter challenges for modelling and materials testing in the fusion context, including the relevance of spallation source neutron testing to fusion materials evaluation.
\end{abstract}

\section{Introduction}

Planned fusion reactors make several novel demands on materials and on basic condensed matter physics. One class of demands results from the nature of radiation damage associated with the $14.06 \mathrm{MeV}$ fusion neutrons (we will use $14 \mathrm{MeV}$ from now on in the paper for simplicity), and the highly non-equilibrium initial processes. These we outline later at the end of this paper. Another class of demands concerns the extreme conditions for plasma-facing materials, with high thermal and particle fluxes, and large, possibly transient, mechanical and

1 Author to whom any correspondence should be addressed. 
thermal stresses. Since the design of the Joint European Tokamak (JET) many new materials opportunities have opened up, and our paper addresses some of the possible ways forward.

The operating conditions inside a magnetic confinement fusion power plant will be extremely hostile to materials. Plasma facing components will encounter at their surfaces very high fluxes of fast ions, neutral particles and radiative heating. Below the surface, materials will experience a variety of transmutations and radiation damage processes induced by interaction with neutrons. The $14 \mathrm{MeV}$ neutrons carry the bulk of the fusion energy and this energy is dissipated in the structures surrounding the plasma. Fusion research is now standing at a crossroads, where breakeven has been approached and the physics requirements for achieving ignition, and beyond to high-energy gain, are clear for both magnetic and inertial confinement [1]. The exploitation of this strong position is now being prejudiced by the lack of a clear set of materials solutions for the realization of power plant designs. This is partly because of the absence of testing of materials in conditions relevant to a power plant and partly because the limited experience gained so far has been on materials that are not suitable for viable power plant designs. Current proposals were both well informed and careful at the time the original decisions were made, but have not always kept up with the major developments in materials taking place in other fields. Robinson [2], the late director of the UK Fusion Programme, identified the development of the longer-term technologies, especially materials required for a power plant, as one of the three interlinked components of the international strategy for achieving electricity generation using magnetic fusion. The other two components are more concerned with the control and behaviour of the plasma: pressing ahead with the tokamak concept; and investigation of alternative approaches with attractive features for power generators.

The number of possible avenues of innovative materials is large. To make the paper more manageable, we will concentrate on three main examples-carbon-based materials, micro- and nano-structured metal alloys, and innovative composite structures. In designing new materials the most important consideration is separation of functionality. 'Function' here might refer to mechanical durability, tritium recycling, ablation protection, thermal conduction, cooling and structural barriers, as examples from a number of competing physical requirements. Moreover, demands vary from the plasma side to the outer structures. Some material immediately facing the plasma may be ablated or fragmented to spall and create dust. The next zone will also experience very high thermal loads, $14 \mathrm{MeV}$ neutron hits, and probably large stresses. Both these regions could become loaded with tritium, so affecting tritium inventories. Further from the plasma, there are structural components, coolant and breeding materials.

Some performance criteria are only related to the surface of the material and some others relate to the bulk; some of the bulk criteria cover the whole of the structure, whereas some can be divided between components. Not all components are subject to significant shear stresses or tension, nor are all components likely to show fatigue. We will investigate this approach in more detail in the paper.

The $14 \mathrm{MeV}$ fusion neutrons introduce new features in radiation damage. They cause primary knock-ons (PKAs) with energies up to $1 \mathrm{MeV}$. This $1 \mathrm{MeV}$ figure is significant, as roughly half the energy losses are from electronic scatter and half from nuclear scattering. There are significant differences in timescale for electronic and nuclear energy loss. Higher energy knock-ons will lose most of their energy by electronic scattering; a regime for which the Norgett-Robinson-Torrens [3] method of calculating displacements is no longer valid. Further, electronic processes may contribute to radiation damage in new ways. Such electronic effects, ignored in most damage studies, must be considered in the context of fusion and fusion materials test facilities. The materials response to different neutron energy ranges is summarized in table 1. 
Table 1. Defect production processes at different neutron energies in crystalline solids.

\begin{tabular}{|c|c|c|}
\hline Neutron energy & Maximum PKA energy $(\mathrm{Fe})$ & Material response \\
\hline$<400 \mathrm{eV}$ & $\begin{array}{l}\text { No elastic } \\
\text { recoils }\end{array}$ & $\begin{array}{l}\text { Radiation damage from recoils from exothermic neutron } \\
\text { reactions in some isotopes. }\end{array}$ \\
\hline $400 \mathrm{eV}-1 \mathrm{keV}$ & $<70 \mathrm{eV}$ & Individually resolved Frenkel pairs. \\
\hline $1-5 \mathrm{keV}$ & $<350 \mathrm{eV}$ & Small well resolved cascade reactions, i.e. separated defects. \\
\hline $5-150 \mathrm{keV}$ & $<10 \mathrm{keV}$ & $\begin{array}{l}\text { Less well resolved globular cascades with interactions } \\
\text { between collisions and defects. Short-range recombination } \\
\text { and cluster formation in the cascade become important. } \\
\text { No significant electronic energy loss. }\end{array}$ \\
\hline $150 \mathrm{keV}-1.5 \mathrm{MeV}$ & $<100 \mathrm{keV}$ & $\begin{array}{l}\text { Larger lobed cascades consisting of overlapping globular } \\
\text { cascades, increasing size of clusters and rate of short-range } \\
\text { recombination. Small electronic energy loss. }\end{array}$ \\
\hline $1.5-15 \mathrm{MeV}$ & $<1 \mathrm{MeV}$ & $\begin{array}{l}\text { Some separate cascades of varying size from main lobed } \\
\text { cascade. Electronic losses comparable to losses by atomic } \\
\text { collisions. Thermal and other effects from electronic } \\
\text { interactions in this energy range not well understood and new } \\
\text { defect production mechanisms may operate. }\end{array}$ \\
\hline$>15 \mathrm{MeV}$ & $>1 \mathrm{MeV}$ & $\begin{array}{l}\text { Separate thermal spike from electronic losses when the PKA } \\
\text { has energies above around } 1 \mathrm{MeV} \text {. Nature of and lifetime of } \\
\text { thermal spike dependent on mean free path of electrons, i.e. if } \\
\text { the material is a conductor or insulator. Possibility of defect } \\
\text { formation from electronic losses is not fully understood and } \\
\text { will be different for materials with different types of bonding } \\
\text {-i.e. metallic, ionic and covalent. Initially the high-energy } \\
\text { PKA is less able to transfer its energy by collisions and the } \\
\text { energy transfers to secondary knock-ons are small. Hence } \\
\text { only small displacement cascades develop along the thermal } \\
\text { spike from secondary collisions and the thermal spike will } \\
\text { end in a large lobed displacement cascade. }\end{array}$ \\
\hline
\end{tabular}

The energy density following a fusion neutron impact is very high, and for more energetic spallation neutrons most of the energy loss would be to electron excitation. We can therefore distinguish between fission neutron damage where a high proportion of the energy deposition is directly to displacements, spallation neutrons where electron energy losses dominate, and fusion neutrons where both processes are significant. For PKAs in the MeV range, electronic energy losses are of the order of a few tens of $\mathrm{MeV} \mu \mathrm{m}^{-1}$ (a few $\mathrm{keV}$ per interatomic spacing) [4]. Thus a high-energy PKA of $30 \mathrm{MeV}$ will travel a few $\mu \mathrm{m}$ before it starts to lose a significant part of its energy to displacements. Overall, one expects a long rod-like damage zone with a few isolated cascades, ending in a displacement spike; the displacement damage is confined to a region of order $100 \mathrm{~nm}$ across. Recent molecular dynamic simulations indicate that local heating can generate defect clusters by a process of punching along close packed directions [5]. Despite the high overall rate of loss of PKA energy to electrons the process of energy transfer to individual electrons is inefficient. Typical energies of excited electrons are around $100 \mathrm{eV} \mathrm{[4];} \mathrm{such} \mathrm{electrons} \mathrm{are} \mathrm{unlikely} \mathrm{to} \mathrm{have} \mathrm{much} \mathrm{effect} \mathrm{on} \mathrm{the} \mathrm{metal} \mathrm{lattice.} \mathrm{Recent}$ results suggesting that electron excitation could directly create defects in metals and particularly bcc and hcp metals, as opposed to fcc [6,7], may be demonstrating local heating as the source of damage. Calculating energy deposition and subsequent thermal conduction is not simple. Even in a high-conductivity metal like copper, the energy will be deposited within a few nanometres 


\begin{tabular}{|c|c|c|c|c|c|}
\hline \multirow[b]{2}{*}{ Concept } & \multirow[b]{2}{*}{ ITER } & \multicolumn{4}{|c|}{ DEMO } \\
\hline & & $\begin{array}{l}\text { Water cooled } \\
\mathrm{Li} / \mathrm{Pb} \text { blanket }\end{array}$ & $\begin{array}{l}\text { Liquid lithium } \\
\text { blanket }\end{array}$ & $\begin{array}{l}\text { Helium cooled } \\
\text { pebble bed blanket }\end{array}$ & $\begin{array}{l}\text { High temp. } \\
\text { helium cooled }\end{array}$ \\
\hline Armours & $\begin{array}{l}\text { Carbon fibre } \\
\text { composites, W }\end{array}$ & \multicolumn{4}{|c|}{$\mathrm{W}$ and $\mathrm{Be}$} \\
\hline Heat sinks & $\begin{array}{l}\text { Dispersion } \\
\text { hardened } \mathrm{Cu} \text {, } \\
\mathrm{CuCrZr}\end{array}$ & \multicolumn{4}{|c|}{ Dispersion hardened $\mathrm{Cu}, \mathrm{CuBeNi}$} \\
\hline $\begin{array}{l}\text { Plasma facing } \\
\text { material }\end{array}$ & $\mathrm{Be}$ & \multicolumn{4}{|c|}{ Carbon fibre-carbon composites } \\
\hline $\begin{array}{l}\text { First wall } \\
\text { structure }\end{array}$ & $\begin{array}{l}316 \text { stainless } \\
\text { steel }\end{array}$ & \multicolumn{4}{|c|}{ Ferritic-martensitic steel } \\
\hline $\begin{array}{l}\text { Blanket } \\
\text { structure }\end{array}$ & $\begin{array}{l}316 \text { stainless } \\
\text { steel }\end{array}$ & $\begin{array}{l}\text { Ferritic-martensitic } \\
\text { steel }\end{array}$ & $\begin{array}{l}\text { Vanadium } \\
\text { alloys }\end{array}$ & $\begin{array}{l}\text { Ferritic-martensitic } \\
\text { steel }\end{array}$ & $\begin{array}{l}\text { SiC-SiC fibre } \\
\text { composite }\end{array}$ \\
\hline Breeder & $\begin{array}{l}\mathrm{Pb}-\mathrm{Li} \text { or } \mathrm{Li} \\
\text { ceramic }\end{array}$ & $\mathrm{Pb}-\mathrm{Li}$ & $\mathrm{Li}$ & Li ceramics & Li ceramics \\
\hline Coolant & Water & Water & Liquid Li & $\mathrm{He}$ & $\mathrm{He}$ \\
\hline Neutron multiplier & $\mathrm{Be}$ & $\mathrm{Pb}-\mathrm{Li}$ & $\mathrm{Li}$ & $\mathrm{Be}$ & $\mathrm{Be}$ \\
\hline
\end{tabular}

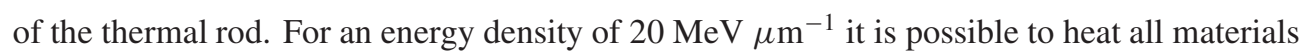
above their melting point over a timescale of the order of $100 \mathrm{ps}$. In the case of insulators this is a very intense pulse, but even for metals we would expect a substantial shock to arise from the expansion. There are several clear concerns: direct interactions between energetic electrons and the ions in the structure; and the thermal effects due to the dissipation of electronic energy to the material. Their importance depends on the material, and especially on whether the material is a metal or non-metal. We will return to this topic in more detail in section 6 .

\section{Defining the problem: current ideas and their challenges}

A range of materials has been considered in design studies for the ITER [8] and DEMO concepts [9]. These are summarized in table 2. The choice of material is affected by chemical compatibility in options for cooling and tritium breeding. Experience in fusion experimental devices has included stainless steels, copper alloys, beryllium, tungsten, molybdenum and graphite, and a number of ceramic insulators. However, the ranges of conditions for fast neutron flux and plasma interactions that will be encountered in a power plant have not been experienced in practice. Austenitic stainless steels are not suitable for fusion power plant structures because of their unsatisfactory neutron activation and lack of stability under fast neutron irradiation. They are likely to be replaced by ferritic/martensitic steels, which exhibit lower neutron activation and greater swelling resistance, but at a price in terms of a slightly reduced operating temperature. Newer materials are being considered. These include, for example, carbon fibre/carbon composites [10], $\mathrm{SiC} / \mathrm{SiC}$ composites [11], vanadium alloys (because of compatibility with liquid lithium), dispersion-hardened copper, and graphite doped with boron. Ehrlich [12] has recently reviewed the current status of fusion materials development.

Preparations are now being made to accelerate the development of fusion power - the "fast track' option [13, 14]. This would see the building of a simpler ITER experimental reactor with a stronger associated programme of technology development, including materials. The 


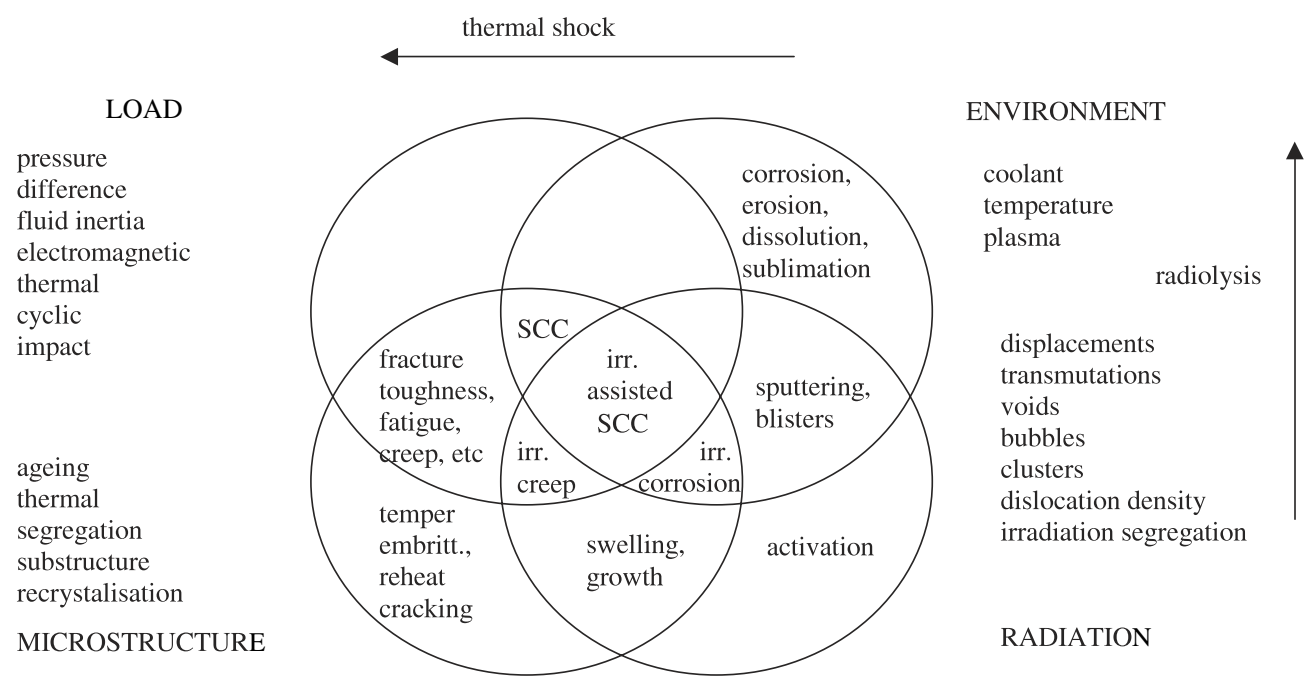

Figure 1. Interacting processes in the structural integrity of fusion reactor components.

Table 3. Estimates of environmental parameters for various fusion reactor design studies.

\begin{tabular}{|c|c|c|c|c|c|c|c|}
\hline \multirow[t]{2}{*}{ (a) } & \multicolumn{7}{|c|}{ Thermal, damage and neutron values } \\
\hline & $\begin{array}{l}\text { Surface energy } \\
\text { flux MW m }{ }^{-2} \\
\text { divertor etc }\end{array}$ & $\begin{array}{l}\text { Surface energy } \\
\text { flux } \mathrm{MW} \mathrm{m}^{-2} \\
\text { first wall }\end{array}$ & $\begin{array}{l}\text { Power density } \\
\mathrm{MW} \mathrm{m}^{-3} \\
\text { first wall }\end{array}$ & $\begin{array}{l}\mathrm{H} \text { from }(\mathrm{n}, \mathrm{p}) \\
\text { reactions } \\
\text { appm/full } \\
\text { power year }\end{array}$ & $\begin{array}{l}\text { He from }(\mathrm{n}, \alpha) \\
\text { reactions } \\
\text { appm/full } \\
\text { power year }\end{array}$ & $\begin{array}{l}\text { Displacement } \\
\text { damage } \\
\text { dpa/full } \\
\text { power year }\end{array}$ & $\begin{array}{l}\text { Total } \\
\text { neutron flux } \\
n\left(\mathrm{~m}^{2} \mathrm{~s}^{-1}\right)\end{array}$ \\
\hline ITER & 10.0 & 1.0 & 15 & 300 & 100 & 10 & $3 \times 10^{10}$ \\
\hline DEMO & 25 & 3.5 & 35 & 1400 & 300 & 30 & $12 \times 10^{10}$ \\
\hline $\begin{array}{l}\text { Power } \\
\text { plant }\end{array}$ & 50 & 10 & 55 & 2300 & 500 & 50 & $20 \times 10^{10}$ \\
\hline (b) & \multicolumn{7}{|c|}{ Temperatures and coolant pressures } \\
\hline Coolant & \multicolumn{3}{|l|}{ Concept } & \multicolumn{2}{|c|}{ Temperature range $\left({ }^{\circ} \mathrm{C}\right)$} & \multicolumn{2}{|c|}{ Load range (MPa) } \\
\hline \multirow[t]{2}{*}{ Water } & \multicolumn{3}{|l|}{ ITER } & \multicolumn{2}{|l|}{$140-190$} & \multicolumn{2}{|l|}{$2-4$} \\
\hline & \multicolumn{3}{|c|}{ DEMO (water cooled Li/Pb blanket) } & \multicolumn{2}{|l|}{$250-500$} & \multicolumn{2}{|l|}{$12-15$} \\
\hline \multirow[t]{2}{*}{ Helium } & \multicolumn{3}{|c|}{ DEMO (helium cooled pebbled bed) } & \multicolumn{2}{|l|}{$250-550$} & \multicolumn{2}{|l|}{$5-20$} \\
\hline & \multicolumn{3}{|c|}{ DEMO high-temperature concept } & \multicolumn{2}{|l|}{$450-950$} & \multicolumn{2}{|l|}{$5-20$} \\
\hline Lithium & \multicolumn{3}{|c|}{ DEMO liquid Li blanket } & \multicolumn{2}{|l|}{$350-750$} & \multicolumn{2}{|l|}{1} \\
\hline
\end{tabular}

programme would allow a power reactor to be built with less risk within 30 years. A key part of this strategy is a programme of materials testing with neutrons at close to the $14 \mathrm{MeV}$ fusion neutron energy and at dose rates near those in power plant structures. Until this can be done we have very limited information on materials behaviour, but what we do know is not encouraging. There is insufficient space here to describe the problem in detail, so we just highlight the main elements of issues for structural integrity.

The materials problems cannot be underestimated, and the options indicated above are not necessarily going to prove to be adequate. Table 3 gives estimates of some of the main environmental parameters for experimental, demonstration and commercial fusion plants as far as can be judged from current design exercises. The range of behaviour related to structural integrity is summarized in figure 1. Structural materials will suffer fast neutron 
damage and as a consequence will undergo dimensional changes from swelling and growth process, the latter in metal with anisotropic crystal structures. In the design of fast breeder reactors dimensional stability from fast neutron induced swelling was a major issue. In fusion reactors the displacement damage level will be higher than in the fast reactor case, but also the generation of hydrogen and helium from transmutations will be around 50 times greater. Further, new effects on microstructure from the higher energy neutrons may be encountered. It is not known if alloys selected on the basis of fast reactor irradiations will be low swelling under fusion conditions. Even if swelling can be prevented, a loss of fracture toughness and sensitization to stress corrosion cracking must be expected in nearly all materials. In fission, it is very clear that structural materials should be tough, and ductile at operating temperatures. For fusion systems, it is far less clear that toughness and ductility are crucial. The stresses are substantially less, not least because the core of a fusion reactor is not massive (unlike that of a fission reactor, in which there are heavy fuel rods and very tight tolerances); indeed, the largest stresses can be those for circulating the coolant. There is the possibility of novel designs to engineer reduced dependence on tough materials. This is a key issue as reduced ductility is more difficult to prevent than other macroscopic effects of fast neutron irradiation.

Consideration of the additional effects of plasma facing materials is important but limitations on space prevents us from giving justice to this topic and we will just high light some of the most important issues.

The plasma and the plasma-facing materials form a coupled system. The plasma itself will be influenced by the ions, electrons, and perhaps hydrogen atoms or molecules coming from the wall, by losses from the plasma species to the wall, and by any changes in the electromagnetic boundary conditions at the wall as it evolves with time. The material of the wall will experience in addition to radiation damage: sputtering both chemical and physical; collision-induced mixing; and thermal gradients and shocks that may result in surface cracking and fragmentation. It is usual for models to emphasize either the plasma or the wall. A recent European review [15] looks at these issues in some detail, but modelling of the wall side in the presence of a plasma is still a subject that has to develop. We must stress the difference between modelling the plasma in the presence of a wall and vice versa. In practical terms, refractory metals $(\mathrm{Mo}, \mathrm{W})$, diamond and graphite have clearly superior properties because of their low thermal expansion coefficients, high strength and high thermal conductivity, making them suitable for armours. Use of dispersion hardening can also allow copper to approach the required performance for limiters and divertors. Choice of materials will always be problematic as a low $Z$ is required in order to reduce effects on the thermal-nuclear reaction on contamination of the plasma, but high is synonymous with resistance to sputtering. Ablated material and dust formation are also an issue that requires resistance to surface microcracking and spalling from blistering as well as condensation of sputtered material.

Tritium retention could prove a problem. There are various strategies to minimize $\mathrm{T}$ retention or its consequences. One might hope to minimize retention by turning to a material with low $\mathrm{H}$ solubility, or perhaps one already saturated with $\mathrm{H}$. This may not prove helpful, since $\mathrm{T}$ could be retained at vacancies created by radiation damage in an operating reactor. Another way might be to create some connected porosity, so as to enable $\mathrm{T}$ to find more rapid routes for transport out of the solid. A third option might be to use a wall material that is continually replaced, the 'waterfall' principle that was suggested in the 1970s. There has been a recent successful demonstration on a small scale using liquid $\mathrm{Li}$ [16].

We will now go on to examine three approaches to providing a new generation of fusion materials that might overcome certain of the problems of engineering a fusion power plant. Some of the suggestions are new and some are developments of previous proposals. 


\section{Carbon-based materials}

Graphite is already a material widely used in fusion reactor plasma-facing surfaces. So far, the conditions have not been demanding, and new issues of tritium retention, chemical erosion and neutron damage will have to be resolved. A promising class of materials is carbon matrix carbon-fibre composites. These materials have the strength and flexibility for use not only as first wall armour but also in more demanding locations, like divertors [10]. In fact, such composites may be the only serious option from the point of view of erosion lifetime together with the requirement for low $Z$. Tritium retention is a major concern, particularly during the deposition of carbon during sputtering after contact with the plasma. Dust production has been a problem with existing graphite facing materials and this is in turn can lead to an increase in the tritium inventory [17]. Some of the larger dust particles come from cracking of thermallyfatigued armour and can be reduced in more sophisticated materials. Smaller particles come from flaking of re-deposited material, and the smallest sizes from condensation of carbon in the plasma. Volume changes do not seem to be a problem with carbon-fibre composites, provided the final graphitization temperature is high enough during fabrication. A decrease in thermal conductivity is expected from displacement damage, but this saturates quickly and is most severe at lower temperatures than are to be expected for an operating fusion reactor. There is a possibility of doping the carbon with $\mathrm{B}, \mathrm{Si}$ or $\mathrm{Ti}$ to reduce erosion and reduce tritium retention [18].

Graphite is not the only carbon option. Diamond-like carbons (DLCs) are possibilities; particularly DLC films that are simple to manufacture and are relatively inexpensive. Controlled deposition of carbon materials from oil vapour or films with ion beams or thermal methods allows for the production of carbon films with a wide range of properties, e.g. diamondlike carbon (DLC) or CVD diamond films, and materials that can flow with predetermined viscosity [19]. Residual hydrogen content and the proportion of diamond type $\mathrm{sp}^{3}$ bonds and graphitic $\mathrm{sp}^{2}$ bonds control the material properties. By controlling the content of hydrogen and the ratio of $\mathrm{sp}^{2}$ to $\mathrm{sp}^{3}$ bonding, the flexibility of the coating can be varied from rigid diamondlike properties to viscous tar-like material to friable material. Thus DLC coatings might be created with chosen visco-elastic properties, able to respond to stresses by compliance rather than fragmentation. We might expect that such films produce less dust than graphite.

Pure diamond films are another possibility. Diamond films are neither outrageously expensive (figures quoted are around $\$ 30000 \mathrm{~kg}^{-1}$ ) nor especially hard to create, and they have superb thermal properties. Diamond has even been suggested for an adventurous direct conversion system based on wide band-gap diamond photovoltaic cells [20]. Diamond films can be deposited fairly readily, and have several major advantages. Sputtering energies correlate well with atomization energies, and so diamond should have greatly reduced sputtering than other materials. The thermal conductivity of diamond films is very high, perhaps a third of that of single-crystal diamond (and single-crystal diamond has a thermal conductivity equal to or better than that of copper). Radiation damage does reduce the conductivity, but even damaged material has strikingly good performance at likely operating temperatures. The high thermal conductivity will minimize the effects of thermal shock, although there is the possibility of spalling of crystallites from the polycrystalline films.

Less is known about fullerenes and graphite nano-tubes, but they have interesting properties and exhibit resistance to radiation damage that has not yet been properly investigated [21]. There is a possibility that they could be included as a stiff porous layer in laminar composites, but it is also possible to make interlinked fullerites that have exceptional hardness and elastic modulus and could be used as hard coatings (e.g. [22, 23]). Application of these more exotic materials rests on the ability to manufacture them efficiently and to 
incorporate them into structures. At the present time DLC and diamond films seem to hold the best promise for immediate consideration. Carbon nano-structures such as fullerenes and graphite nano-tubes [24] can be made in relatively economical forms, the so-called 'bucky grass'. Whilst the tubes alone are probably too fragile to be plasma-facing as created, one could envisage them incorporated in a DLC matrix, for which they would provide routes to aid release of implanted tritium.

Let us try to assess the possible advantages of diamond or diamond-like carbons to fusion reactors before exploring radiation effects. There are certainly some potential advantages of this class of material, such as:

(a) Diamond has one of the highest thermal conductivities known; even diamond films have higher thermal conductivity than many metals (and certainly better than stainless steels).

(b) The diamond-like carbons (DLC, a-C:H) include composition ranges for which the viscoelastic properties can be controlled, and hence there is the opportunity to have a material that is self-healing in response to induced stresses, and to some aspects of radiation damage.

(c) The elements involved are only $\mathrm{C}$ and $\mathrm{H}$ (of course, traces of other species like $\mathrm{O}$ and $\mathrm{N}$ are hard to avoid), which are relatively benign as regards the plasma itself (see (f), (iii) below).

(d) Diamond films and DLC can be deposited over large areas by a variety of methods. In particular, one successful method of coating complex structures with DLC has proved to be the dipping of the component into a hydrocarbon (or a vacuum oil) followed by bombardment with low-energy $\mathrm{N}$ ions, which knock out hydrogens, leading to crosslinking to form DLC strongly bonded to the surface. We emphasize that all DLCs are not the same, and depend to some degree on the initial hydrocarbon [25], which has implications for radiation response. Convertino et al [26] quote tuning of the electronic properties of DLC using plasma-enhanced CVD, and were able to produce DLC with an optical band gap close to that of diamond.

(e) Diamond has a high displacement energy (probably about $80 \mathrm{eV}$ ) and is therefore rather robust against irradiation. The high atomic binding energy will also imply good sputter resistance. The radiation response of DLC has not been investigated in detail to our knowledge, but will have certain trends (see, for example, section 4.3 of [27]). Some of these are known from lithography, in which radiation (UV or electrons) is used to modify polymer structures.

(f) The presence of hydrogen in carbon coatings has been shown to suppress carbon erosion at high flux bombardment [28].

(g) Diamond bonding is stable to temperatures at least as high as $1000 \mathrm{~K}$, and in pure single crystals graphitization is not seen until around $1700 \mathrm{~K}$ [29], although in less pure films the transition is likely to be at a lower temperature. Stability under irradiation is not yet fully understood (see below).

(h) The strength of diamond is comparable with engineering materials, although it is intrinsically brittle. The tensile strength increases with decreasing grain size, and DLC and CVD films have good hardness and tribological properties [30, 31].

The radiation performance of carbons is closely related to the behaviour of hydrocarbons and polymers. The deliberate use of hydrogen to modify carbon properties and the presence of hydrogen isotopes from the plasma and other contaminants makes it useful to look at the effects of radiation (both ionizing radiation and displacement damage) on polymers. The main processes are scission (in which random breaks in the chain occur, rapidly reducing chain 
length) and depropagation (which generates the monomer, as in polymethylmethacrylate). The effects of increasing dose show a range of phenomena [32, 33]. For $2 \mathrm{MeV} \mathrm{Ar}^{2+}$ ions, for example, doses of $10^{14} \mathrm{~m}^{-2}$ and above show basic beam-induced structural effects: polymerization of monomers or dissociation of polymers. Doses above about $10^{15} \mathrm{~m}^{-2}$ begin to indicate scission or cross-linking, and basic lithographic processes (in lithography, it is the smaller units which are dissolved away, so cross-linking gives negative resists, where the irradiated region is less soluble; scission gives a positive resist since the irradiated regions are more easily removed). The presence of species like oxygen, which can react with free radicals, becomes especially important when doses exceed $10^{16} \mathrm{~m}^{-2}$ (a free radical R- becomes ROO-; this reacts with $\mathrm{R}^{\prime} \mathrm{H}$ to give $\mathrm{ROOH}$ and $\mathrm{R}^{\prime}-$ and degradation can continue). For still higher doses, above $10^{17} \mathrm{~m}^{-2}$, carbonization occurs, with associated effects on electronic transport. It is the carburization that appears to be associated with the insulator-metal transition in both polymers and diamond-like carbon. In essence, the radiation leads to regions of carbon from which hydrogen has been released (whatever its fate); the carbonaceous regions are relatively conducting, like graphite. As the dose rises, the conducting regions overlap until there are percolation paths through the polymer, so it is macroscopically conducting. There is here scope for descriptions in terms of Poisson distributions of local damage, normally expressed in terms of tracks with a defined radius [34].

There can be cross-linking of chains as well as breakup. This yields a more rigid and more brittle structure. Roughly speaking, cross-linking is favoured when the chain carbons are linked to $\mathrm{H}$, whereas degradation occurs when they are linked to other $\mathrm{C}$ atoms. Thus irradiation removes hydrogen, but hydrogen itself promotes the production of the rebonding and cross-linking in the film. In simple terms the matrix becomes stiffer and more carbonlike, while at the same time hydrogen and volatile hydrocarbons are generated. In tars and bitumens this produces the macroscopic effects of swelling and cracking [35]. The solubility of hydrogen and other gases is significant, so release to the surface will be important for thin layers so swelling is not likely to be to important. Cross-linking dominates in polyethylene, polystyrene and polymethylacrylate; it increases the cohesion and resistance to chemical attack of the polymer, and may also lead to shrinkage. Degradation dominates in polyisobutylene, polyalpha-methylstyrene, and polymethyl methacrylate. Gas (e.g. hydrogen) may be evolved. These results, mainly from polymer radiation damage, are also consistent with rules used in lithography, where the Ohnishi parameter [36] indicates that dry etch resistance is improved by increasing the relative amount of carbon in the polymer architecture.

High-carbon materials are sensitive to both temperature and pressure in their irradiation behaviour. Diamond bonding is favoured at high pressures and moderate temperatures, while graphite is favoured at higher temperatures. At low temperatures the materials will amorphize under displacement damage. The process starts at about $0.1 \mathrm{dpa}$ and is complete at $0.5 \mathrm{dpa}$ [37]. For temperatures between 600 and $750 \mathrm{~K}$ at $10^{-6} \mathrm{dpa} \mathrm{s}^{-1}$ the diamond structure has been observed to be stabilized, with the temperature range for which diamond is favoured extended upwards as the damage rate is increased [38]. Studies of fast neutron damage of diamond, with doses in the range $1.3-2.5 \times 10^{25} \mathrm{~m}^{-2}(\sim 1 \mathrm{dpa})$ at temperatures between 723 and $803 \mathrm{~K}$, show the formation of an intermediate triclinic structure of distorted graphite layers cross-linked with diamond type $\mathrm{sp}^{3}$ bonds [39]. This study also indicates the conversion of graphite formed by irradiation back into diamond after annealing at $1423 \mathrm{~K}$. Other studies have shown that the level of $\mathrm{sp}^{3}$ bonding increases when graphite is irradiated at temperatures greater than $700 \mathrm{~K}$ [39]. This is clearly an area that will need further study if diamond and DLC are to be candidates for fusion application.

Microwave water plasmas (as proposed for various medical and microelectronic applications) also modify polymer surfaces, so we should be prepared for similar effects 
when plasma contacts walls in the fusion reactor situation. Thus in a combination of processes (adsorption, desorption, random bond breakage perhaps by $\mathrm{O}\left({ }^{3} \mathrm{P}\right)$, surface diffusion, hydroxylation, removal of volatiles, etc) the polyamide forms hydroxyl species, and the surface morphology changes. Both changes contribute to changes in adhesion behaviour [40]. Photoablation by excimer laser irradiation $(248 \mathrm{~nm})$ appears to lead to another type of change. Conical defects appear (rather than the pits from etching) and the ablation rate diminishes with time. What seems to be happening is that the polymer 'radiation hardens': regions that are more carbonaceous are less easily ablated, and initiate cone formation [41], as one would expect from analogies with $[34,42]$. The specific problem of contact with various hydrogen species specific to the fusion environment is reviewed in [43].

The composition of the surface region exposed to the plasma will change with time. This is perhaps the most critical set of issues that will determine the acceptability of innovative carbon coatings for fusion applications. The major effects include:

(i) Removal of material: see (e) above; note also that excited hydrogen species may be more effective at removing $\mathrm{C}$ (the effect of excited $\mathrm{H}$ species on $\mathrm{BN}$ is discussed by [44]).

(ii) Mixing will alter the depth distribution of $\mathrm{C}$ and $\mathrm{H}$; for example, see [45].

(iii) Implantation of $\mathrm{H}(\mathrm{D}, \mathrm{T})$ is perhaps the most interesting, since one does not wish there to be a hydrogenic reservoir altering the plasma composition or accumulating T. Presumably the DLC could be made as a-C:D, rather than a-C:H. Possibly, it could be doped with Li and breed enough $\mathrm{T}$ to maintain a steady state composition. 'Subplantation' of $\mathrm{C}$ is one of the ways to get ta- $\mathrm{C}$ (an amorphous carbon without much $\mathrm{H}$ ). There is also a discussion of molecular dynamics modelling by [46], which looks at $\mathrm{C}$ atoms with energies in the 10$150 \mathrm{eV}$ range incident on an a-C surface. The molecular dynamics suggests that growth is most effective between 40 and $75 \mathrm{eV}$. Growth involves implantation above about $10 \mathrm{eV}$. Robertson [47] makes the points that if one deposits on a substrate much above $250{ }^{\circ} \mathrm{C}$, the fraction of $\mathrm{sp}^{3}$ starts to fall; however, if one deposits at room temperature, then the $\mathrm{sp}^{3}$ remains stable up to $1100^{\circ} \mathrm{C}$, although the optical gap (more associated with $\mathrm{sp}^{2}$ ) starts to fall at $700^{\circ} \mathrm{C}[48]$.

In summary, there is very considerable scope for designing a carbon-based material for those regions closest to the plasma. Carbon, as some form of graphite, has been a respectable first wall material in many fusion experiments. There is a significant variation from one carbon source to another. The important opportunities stem from the fact that some forms of carbon have outstanding properties. New carbon materials, especially those based on diamond films (new in the 1980s), diamond-like carbons (effectively new in the 1970s), and bucky carbons (flourishing from the 1980s) have evolved greatly in the last decade, and offer significant new opportunities. Even the amorphous diamond-like carbons can have high thermal conductivities and, since their viscoelastic and other mechanical properties can be adjusted by control of their hydrogen content, they could prove valuable components of a wall material. Diamond itself (as CVD diamond film) has outstanding properties, and is said to have much lower sputtering rates than graphite. Clearly, it sustains damage, but the thermal conductivity at likely operating temperatures is expected to be very good.

\section{Nano-structured alloys: can swelling be suppressed?}

Is it possible to design alloys that have negligible swelling? Real engineering materials vary greatly in their swelling behaviour. It has been suggested that all metals have the potential to swell at high rates, and the only difference is the incubation period before swelling starts [49]. It is conceded that maximum swelling rates in ferritic steels are about $20-30 \%$ of those in 
austenitic steels, but this will still limit the life of components to just a few dpa from the time that swelling starts.

The clues to alloy design come from the underlying processes of radiation damage and the causes of the incubation behaviour. We suggest that it is indeed possible to design low swelling alloys. Indeed, the same principles can be used to minimize growth and radiation creep and, to some extent, the microstructural changes that control hardening and embrittlement. The interstitials and vacancies formed in the first stages of radiation damage do not simply recombine. There is a separation to different sinks of some of the interstitials and vacancies formed during displacement damage. We get swelling because interstitials preferentially go to interstitial loops and dislocations, leaving a supersaturation of vacancies that can precipitate into voids. There is growth because interstitials and vacancies go to sinks with different orientations in the material, and we get irradiation creep because interstitials and vacancies interact in a complex way with dislocations and loops in the material. If vacancies and interstitials recombine, then the effects of radiation damage are eliminated. If vacancies and interstitials go to the same sinks, then the effect is the same as recombination.

Incubation of swelling occurs mainly because of high initial sink strengths in the material. As noted above, pure metals and simple alloys have higher swelling rates. Garner et al [49] quote observations of simple ternary alloys of $\mathrm{Fe}-\mathrm{Ni}-\mathrm{Cr}$ and binary alloys of $\mathrm{Fe}-\mathrm{Cr}$, as well as pure Fe, that show very low incubation doses. Real stainless and ferritic steels show much higher incubation doses. In stainless steels, three main processes are responsible: (i) trapping of point defects on solute atoms slows diffusion and increases recombination; (ii) carbide precipitates pin high dislocation densities; (iii) small precipitates have high sink strengths for point defects, so reducing the overall defect concentrations. All these processes compete for point defects and prevent swelling. However, at high doses, radiation coarsening of precipitates and radiation-assisted segregation of solutes allows point defect concentrations to rise to levels such that voids can nucleate. Additions of stabilizing elements to steels, e.g. Ti and Nb, slow the process of carbide coarsening and delay the onset of swelling. When carbide precipitates are fine, they form neutral sinks that mop up both vacancies and interstitials, but when they are coarser they can form nuclei for voids and can enhance swelling rates.

The secret for designing alloys is therefore to find a way of introducing a dominant concentration of sinks for point defects that is stable enough to survive the high displacement doses and gas production in a fusion reactor. This could be in the form of a multiphase material with a fine microstructure, a material containing a very fine dispersion of an incoherent second phase, or stable nano-sized grains or a nano-structured composite. Such structures may also have advantages relating to the behaviour of helium. The two most effective ways of limiting damaging effects of helium are: (i) to diffuse it to a surface where it can be released; and (ii) to trap it on a fine dispersion where swelling is limited by surface energy effects and voids are not nucleated because the sink strength is too high and the vacancy supersaturations are not high enough. Nano-structured materials can provide both these situations.

The use of very fine microstructures can limit some macroscopic effects of radiation damage, but some hardening and embrittlement will occur particularly at lower temperatures. This is because cascade processes produce fine dispersions of point defect loops, and even if these migrate, disperse or are annihilated they are constantly being replaced in new cascades. At high displacement damage rates there will always be fine dispersions of hardening obstacles that will raise the yield strength and decrease the ductility. Nano-structured materials themselves are intrinsically hard and have lower fracture toughness [50]. Fast neutron damage will make this worse. However, this is not a critical issue for fusion components, and the elimination of large dimension changes with radiation is more difficult to design against than low fracture toughness. 
One way of achieving a high sink strength nano-structure is with dispersion-strengthened alloys. Indeed these are now receiving attention for use in fusion power systems. The main reason has been the improvement of creep resistance, but beneficial effects on irradiation performance may be more important. The use of a coherent finely dispersed phase is one of the reasons for low swelling in nickel-based superalloys with $\gamma^{\prime}$ and $\gamma^{\prime \prime}$ precipitates. Here the mismatch dislocations on the interface boundaries trap point defects and promote recombination. The dispersion should be as fine as possible and preferably with a particle size of around $10 \mathrm{~nm}$ or less and the spacing between 10 and $100 \mathrm{~nm}$. Large surface area particles will be more effective than spheroidal ones. As well as reducing damage through defect recombination the inclusions limit the possible free path of dislocations, making embrittlement from channel fracture less likely.

Ferritic steels have been high on the list of candidate structural materials because they are intrinsically low swelling and can be formulated to have low activation from transmutation, but not least they are familiar engineering structural materials that are relatively cheap to manufacture. The main problem is that they lack high temperature strength and corrosion resistance compared to austenitic stainless steels. For this reason most of the steels currently being considered have $\mathrm{Cr}$ contents in the range $9-12 \%$ for corrosion resistance, significant carbon levels to promote the formation of martensite for strength and swelling resistance, and substantial levels of hardening elements $\mathrm{W}, \mathrm{Mn}$ and $\mathrm{V}$ in order to have creep rupture resistance [51, 52]. Ductile-brittle transition temperature (DBTT) shifts are at a minimum for a $\mathrm{Cr}$ level of $9 \%$. Most data on such steels from fast reactor studies have Mo and $\mathrm{Nb}$ at significant level and in optimized fusion alloys - these elements are replaced by $\mathrm{W}$ and Ta. So far irradiation experience has been very small, but preliminary studies show that such ferritic steels above the DBTT retain significant ductility and do not swell [53]. The swelling resistance comes from the highly strained fine martensitic microstructure, stabilized by carbide precipitates. However, new data show swelling at a rate of around $0.2 \%$ dpa for displacement doses above $150 \mathrm{dpa}$ [40]. The use of oxide dispersion strengthened (ODS) variants on these steels may be the only option if fusion structures need to be used at very high doses.

The poor high-temperature strength of ferritic steels was seen as a problem for fast reactor fuel cladding applications so, in the 1980s, there was a lot of interest in ODS ferritic steels [54]. Powder metallurgical or mechanical alloying methods are used to create a fine dispersion of $\mathrm{TiO}_{2}$ or $\mathrm{Y}_{2} \mathrm{O}_{3}$. This approach is now seen as real option for fusion applications $[55,56]$. The advantages are not just confined to high creep-resistance, but also can lead to a reduction in radiation damage effects. Some limited studies of ODS steels ion-irradiated with He confirm that such alloys have lower swelling than standard ferritic steels even with high levels of gas [57]. There is also a possibility that ODS vanadium alloys [58] and ODS copper alloys $[59,60]$ may prove useful.

The main disadvantage of ODS alloys is the difficulty of fabrication, and particularly welding. Heat working and heat treatments to induce recrystallization have been used successfully to fabricate tubes for fast reactor fuel rods, but fabrication costs will inevitably be higher than with conventional ferritic/martensitic steels. In situ formation of oxides might be possible, although the first attempts at internal oxidation have not produced sufficiently high volume yields of the dispersant [61]. Another possibility is the precipitation of TiN dispersions in steels, where the nitride can be precipitated after fabrication [62]. The TiN precipitates have a good shape for blocking dislocation movement and a high surface area.

An alternative to ODS strengthening of copper alloys has been proposed very recently, using technology originally developed for making superconducting cables. Such cables are made by drawing a composite bundle of superconducting intermetallic wires embedded in a copper matrix. When the superconducting material is replaced by pure $\mathrm{Nb}$, an interesting 
effect is observed as the bcc $\mathrm{Nb}$ is not able to deform so freely as the fcc $\mathrm{Cu}$, since it has fewer slip systems. As the structure is drawn down to the scale of a few tens of nanometres, the $\mathrm{Nb}$ forms convoluted ribbons. For $18 \mathrm{wt} \% \mathrm{Nb}$, the ribbons can be as small as $6 \mathrm{~nm}$ thick and spaced by around $60 \mathrm{~nm}$, with a coherent interface with the $\mathrm{Cu}$ matrix. The resultant material retains a high fraction of the $\mathrm{Cu}$ thermal and electrical conductivity, but exhibits an extraordinary strength of up to $1500 \mathrm{MPa}$ [63]. Such materials are now being used to construct pulsed magnets, which require these properties. Experiments are now being made to replace the niobium with vanadium to make a high strength, high thermal conductivity armour, that is also likely to have good radiation damage resistant properties [64].

In the 1980s there was much interest in developing austenitic steels with optimized activation properties. These steels would have manganese to replace nickel to replicate austenitic steel characteristics. About twice the atomic proportions of Mn are needed to give a structural effect to match that of $\mathrm{Ni}$ [65]. Fast reactor irradiation showed that such steels were comparable to Ni-based steels in swelling and response of mechanical properties [66]. Interest in these steels seems to have waned and, as far we can tell, no work has been done to optimize the behaviour of these steels in terms of carbon content, stabilization, etc. They do have the advantage of not being ferromagnetic, and the possibility of reducing swelling and helium effects by introduction of a fine oxide or nitride dispersion could make these materials attractive for fusion design studies again. The use of a TiN dispersion version of the tailored alloy would be well worth investigation. We conclude that there is significant scope for the design of effective nano-structured alloys.

\section{Composite structures: separating functions}

There are possibilities of more exciting materials being designed specifically for the fusion reactor environment. Kelly [67, 68] suggested the use of lasagne-structured materials for first wall construction, to allow the release of hydrogen and helium formed by transmutation. As noted above, the idea of a composite mesostructure is important. At this stage, we need to keep open minds on what is possible. Composite structures may include liquid as well as solid phases, and the scale of the structure is a key variable in controlling response. The thickness of the layers could be a critical variable, and a combination of a porous separating layer and a strong structural layer would form the basic building blocks. Layered materials on the nanoscale can exhibit unusual electromagnetic and mechanical properties that could also be used to increase the effectiveness of components [69].

Kelly et al [68] have approached the problem and have proposed composites comprising fibres that are themselves composed of nano-thickness ribbons of ceramic or carbon materials. The fibres would provide strength, while the interface with the matrix material would be controlled to have a balance between transmitting load from the matrix to the fibre and providing an energy absorbing mechanism by nano-cracking of the material in the interface. The small thickness of the ribbons making up the fibres would allow point defects and gas to escape. The matrix would perhaps be a metal alloy with controlled porosity to accommodate swelling and interfacial mismatches. The resulting material would be the fusion designers' equivalent of wood - a material that is strong but gives warning of fracture and fails with a high energy dissipation, and expires transmutation products and defects like wood transpires water and gases. This is not fanciful—who would have predicted 50 years ago that strong high-modulus fibres could be pulled from toasted polymer filaments used in the textile industry? To make Kelly's ribbon fibres we could look to the techniques of the candy maker and superconductor manufacturer for building a composite bundle of initially ductile polymers, metals, fine grained ceramics or glasses that could be drawn to the required 
diameter and then transformed by heating in suitable environments to create the composite ceramic fibre.

Our own view is that the aim should be to create a composite structure in which the main functional features are separated and shared between the components. For armour plates or structural walls, the structure would have elements that handled the surface, bulk response and structural issues that we have identified above. The concept of separation of functionality can be applied at various levels in the structure.

The first wall is there only to provide the primary layers of protection in front of the tritium blanket. It has to support itself, and withstand the thermal loads, the occasional plasma contact and the various radiation fields. The energy deposited in the wall has to be removed and in power reactors taken to generate the power. Limiters, divertors and other structures that get closer to the plasma have higher erosion rates, but they are similar in their requirements to the wall.

The surface layer has to resist erosion, and its properties should be optimized for that purpose. If it is thin enough, its strength is not an issue. In fact it could take the form of a viscous liquid or a hairy pile of refractory fibres. The load-bearing structure need not have the full thermal resistance properties if the structure is designed well, but it has to have sufficient strength to support the rest of the structures and not undergo large dimensional changes from radiation damage. The design could arrange for most of the loads to be compressive so that low fracture toughness but strong ODS alloys could be used. One way of approaching this is to use a stable kinematic structure analogous to a stack of spheres of material, like the stacks of cannonballs still seen in military museums. The framework is stacked to provide the support for the first wall, breeder, coolant channels and some of the magnet coils. It could also contain tritium breeding materials, absorb most of the neutron energy, and act as the biological shield. Its modular stacked structure would also make eventual decommissioning easier.

The load-bearing containment of the coolant channel will have to support tensile loads, but need not be compatible with the coolant or leak-tight. Oriented fibre-strengthened composites would be suitable for this purpose. The inner layer or layers next to the coolant would provide chemical compatibility and seal the coolant channel; provided it can deform it need not be very strong. The rest of the wall structure has to conduct heat well and not undergo large dimensional changes, but need not have much strength or rigidity.

An obvious way of protecting a surface is to provide it with a coating of material with the desired surface properties but with less good bulk properties. We have already discussed diamond and other carbon coatings. Other candidates are plasma spray coated ceramics such as alumina, but $\mathrm{B}_{4} \mathrm{C}$ is a strong candidate combining low $Z$ properties with high strength and corrosion resistance [70]. A problem with such ceramic coatings on metals is delamination and cracking because of large differences in thermal expansion, so practical coatings have to have buffer layers or the structural material has to have its properties modified, for example by incorporating ceramic fibres to reduce the macroscopic expansion coefficient. Adjacent to coolants, a fibre-reinforced channel could be lined with a ductile metal layer operated above $\frac{1}{2} T_{\mathrm{m}}$ (to ensure plasticity and prevent radiation damage) where the chemistry is controlled to produce a self-sealing oxide passive surface coating.

Laminar composites are attractive for the main wall material. They are simple to fabricate, and control can be exercised over the thermal properties and radiation damage. To withstand thermal loading, the layers have to be decoupled mechanically while retaining a high thermal conductance. Combinations of different forms of carbon or alternating ceramic-metallic layers could be considered. The use of layers of graphite nano-tubes or metallic aero-foam between layers of other material would be one way of venting gases while retaining some strength and rigidity. Another possibility is to use a porous matrix to hold a liquid phase or to use a felt or 


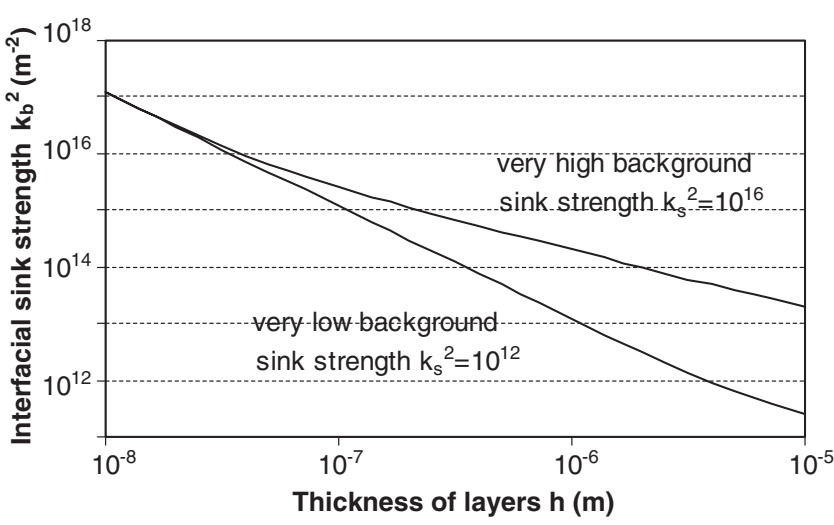

Figure 2. Variation of surface sink strength of thin films as a function of thickness for the range of background sinks normally encountered in radiation damage.

a woven mat of fibres. The liquid could be liquid lithium [71], a molten lithium salt [72] or a carbonaceous material, and the matrix could be carbon, tungsten or some other metal.

For thermal loading, the thickness of the layers needs to be around $1 \mathrm{~mm}$ or smaller, provided they are sufficiently decoupled. But what about the thickness to limit the effect of radiation damage? The surfaces or interfaces between the layers need to be stronger sinks for point defects and gas atoms than the loops, dislocations and voids that produce the radiation damage effects. Using rate theory it is easy to calculate the sink strength for infinite plates. For planar films the surface sink strength, $k_{\mathrm{b}}^{2}$, is a function of the thickness of the film, $h$, and the total strength of other sinks for the defects, $k_{\mathrm{s}}^{2}$ :

$$
k_{\mathrm{b}}^{2}=k_{\mathrm{s}}^{2} \tanh \left(\frac{1}{2} k_{\mathrm{s}} h\right) /\left[\frac{1}{2} k_{\mathrm{s}} h-\tanh \left(\frac{1}{2} k_{\mathrm{s}} h\right)\right] .
$$

When the surface dominates as a sink, the sink strength goes to $k_{\mathrm{b}}^{2}=12 / h^{2}$. The range of behaviour for variations in $h$ and $k_{\mathrm{s}}^{2}$ is shown in figure 2. Sink strengths of $10^{16} \mathrm{~m}^{-2}$ are exceptional and are only encountered at low temperatures at high displacement doses. In the range of temperature where swelling can operate, typical background sink strengths are around $10^{14} \mathrm{~m}^{-2}$. To inhibit swelling or to release He films less than $100 \mathrm{~nm}$ thick will reduce point defect levels, but thinner films will be even more effective. It is feasible to produce such films using current PVD and CVD technology at rates sufficient for making engineering structures.

\section{Condensed matter challenges: defect production processes}

Modelling of materials should provide a way of assessing materials for their performance in fusion reactors. In addition, it can provide the link between experiments in test facilities and behaviour in full-scale engineered structures. However, modelling presents challenges to condensed matter scientists almost as great as the experimental ones. In general, the modelling of radiation damage has been difficult and often controversial. Fortunately, there has been a lot of progress in direct simulation using molecular dynamics calculations. Here we will concentrate only on the issue of defect production, which is central to all damage modelling. For fusion reactor structures, most of the energy in PKAs is going into cascades with over 10 times the energy of the cascades in fast reactor irradiations. Higher energy cascades are less efficient at producing displacements by atomic collision processes, so in terms of displacement damage the higher energy tail in the distribution will decrease rather more sharply.

Radiation damage is conventionally measured in displacements per atom. The calculation of the displacement rate from the neutron spectrum involves a range of assumptions and a 
particular model of the damage process. The current convention for this calculation, the Norgett-Robinson-Torrens (NRT) method [3], has recently come under scrutiny, particularly after molecular dynamic simulations of the damage process for energetic PKAs up to $50 \mathrm{keV}$. Fusion materials design will assess damage production partly from neutron sources with properties different from those of likely fusion reactors. The evaluation of neutron sources needs an accurate understanding of energy dissipation and atomic displacement, and this raises important issues.

It takes a few tens of electron-volts to knock an atom out of its lattice position, and energy characterized by the so-called displacement energy. Displacement is anisotropic, so arriving at the right average value is difficult. In compounds, the displacement energy can be different for different component elements. Metals have lower displacement energies, covalent and ionic solids rather higher energies. A neutron scattering event can displace a host atom nucleus from its lattice position if sufficient kinetic energy is transferred, creating a vacancy and an interstitial, the Frenkel reaction that is the basic process for displacement damage. The flow of the interstitials and vacancies to different sites drives the processes that lead to the macroscopic effects of radiation damage, such as embrittlement, swelling, irradiation induced creep and growth, and decreases in thermal and electrical conductivity.

The PKA, if it has sufficient energy, can produce secondary displacements, and for high energies a cascade of displacements (see table 1). The NRT displacement damage calculation is a development of the simple earlier ideas of Kinchin and Pease [73], and has proved useful as a fast method for estimating the number of displacements. However, the NRT model is increasingly unreliable at the higher energies that become significant for fusion systems. This has partly been addressed by calculating displacement cross-sections with more complete models for electron excitation and the atomic scattering process (e.g. Huang and Ghoniem for $\mathrm{SiC}$ [74]). At low energies, the scattering is approximated well by a hard sphere model, and all energies up to a maximum are equally probable. For higher energies, screening from inner electrons is less effective, and the scattering becomes less efficient for high-energy transfers, becoming inversely proportional to the square of the energy transfer. Electronic energy transfer increases in proportion to the PKA velocity, although the interaction process changes at very high energies, starting to resemble fission fragment damage. Hence the electronic energy loss rate has a maximum for PKAs of the order of a few $\mathrm{MeV}$, the position of the maximum depending on the material. Thus, at low energies, most of the energy goes into atomic collisions, creating displacements or exciting thermal vibrations. Electronic energy losses start to become significant for PKAs above about $10 \mathrm{keV}$, and dissipate most of the energy for PKAs above about $100 \mathrm{keV}$. At very high energies, the PKA will start with a separate spike or track, sometimes called a thermal spike, although the large electronic excitation makes the description of 'heating' simplistic (see chapter 11 in [75]). The dimensions of the spike and its duration will depend on how the electrons can transfer their energy to the lattice and subsequent ion behaviour. Metals and insulators will have large differences in behaviour and the range of electronic excitation phenomena.

Along the spike, there will be occasional secondary knock-ons, but the resulting cascades will be small because of the high energy atomic scattering behaviour. As the PKA loses energy the mean free path for atomic collision will decrease until the thermal spike ends in a displacement cascade. The presence of the spike and high electron excitation will certainly have implications on defect production and other microstructural process, such as resolution and obliteration of existing structures. This is rarely discussed, but will be a major process in material irradiated with fusion neutrons.

Molecular dynamics has proved an invaluable tool in understanding the processes in a displacement cascade. Progress has been limited by computing capacity, by the availability 
of good interatomic potentials for materials of interest, and by the belief that the only role for electrons is as the source of interatomic potentials (a point to which we shall return). Prior to large-scale simulations, various models were developed to try to explain the macroscopic behaviour and observed microstructures in irradiated material. Key issues were the possibility of immediate recombination of self-interstitials and vacancies (removing the effects of irradiation) and the formation of defect clusters that could nucleate microstructural features like voids and cavities. These models built on the idea that a series of atomic collisions would project interstitials away from the path of the PKA. The separation of vacancies and interstitials would occur through replacement sequences and the channelling of interstitials along close packed directions [76]. Thus the cascade would consist of a core of vacancies surrounded by a cloud of interstitials. The high concentration of vacancies at the centres would promote clustering of vacancies, as observed in some (but not all) metals. This qualitative description has been verified in most essentials by molecular dynamic calculations. However, for PKAs in the energy range $0.1-40 \mathrm{keV}$, the efficiency of Frenkel pair production is found to be significantly lower than from NRT calculations, and the efficiency decreases with increasing PKA energy. This could be due either to less efficient use of the collision energy or to shortrange recombination of interstitials and vacancies. The production efficiency is sensitive to the both the crystal structure and the material. Cascades above $1 \mathrm{keV}$ are not found to be very coherent sets of atomic collisions. A more representative picture is of an expanding zone of disorder that collapses, leaving behind the defects. Above about $10 \mathrm{keV}$ the cascades are made up of several overlapping subcascades. The separation of vacancies and interstitials is observed, as is the formation of vacancy clusters. The surprise is that interstitial clustering is also common. Again it is sensitive to the material; clusters tend to be more common at higher PKA energies, and the number of interstitials in the clusters also increases. The fraction of interstitials in clusters of at least two interstitials is between 50 and $80 \%$ for PKA energies above $1 \mathrm{keV}$ [77]. This observation is very important as it has large consequences on the mechanisms for microstructural evolution and macroscopic effects.

Molecular dynamics simulations have been remarkably fruitful in understanding the damage processes, and they have even had an impact on the development of mesoscale models [78]. But they are certainly not a complete substitute for experiment, nor for calculations of other types. Three immediate issues should be noted. First, computational limitations restrict PKA energies to around $40 \mathrm{keV}$, significantly less than needed for representative modelling of the effects of fusion neutrons, even after adjustments for electronic losses are taken into account. Secondly, the potentials used (usually pair-potentials or embedded atom potentials for metals) have known weaknesses even for simple defects and near equilibrium properties. Moreover, most calculations are for elements, or at most binary alloys. Other technical issues include questions of boundary conditions and thermal constraints. Thirdly, the electrons have not been adequately accounted for in the calculations. It is necessary to look more closely at the extent to which electronic excitation leads to modified interion forces, to temporary energy storage, and to energy redistribution in space.

A particular concern relates to MD simulations of bcc metals and particularly iron, where the current pair or embedded atom potentials are not adequate. This is reflected by the failure of current potentials to reproduce stacking fault energies or even to predict lowest energy crystal structures despite fitting elastic constants and other physical parameters well. Until this is resolved the results of molecular dynamic simulation for defect behaviour (migration and small cluster energies) and cascade development will have to be treated cautiously. The problem is not insoluble, and progress has been made with potentials like bond-order potentials, that use a tight-binding model to find approximations for moments of the electron density, to give a better representation for other bcc metals and alloys [79]. 
Table 4. Fast processes under irradiation. These results are mainly for metals, since comparable data are lacking for insulators. The characteristic times of Finnis and of Landau relate to the transfer of energy from nuclei to electrons. The characteristic time of Sigmund relates to energy transfer at the end of a collision cascade; electrons are not explicit. There are further processes with longer characteristic times, such as radiative processes (nanoseconds or slower) and non-radiative energy transfer of electronic excitation energy to phonons, where the times will be very system-dependent.

\begin{tabular}{ll}
\hline Faster than ps & \\
\hline $0.2 \mathrm{fs}$ & Typical plasma oscillation period \\
$0.6 \mathrm{fs}(\mathrm{Ni}) 1.5 \mathrm{fs}(\mathrm{Cu})$ & Electron collision time for liquid metal \\
$70 \mathrm{fs}(0.07 \mathrm{ps})$ & Typical lattice vibration period \\
$100 \mathrm{fs}-10 \mathrm{ps}$ & Self-trapping (for zero barrier) \\
$100 \mathrm{fs}(\mathrm{Ni})$ & Characteristic time [80] \\
$100 \mathrm{fs}-1 \mathrm{ps}$ & Loss of memory for excited electron momenta \\
\hline Times of a few ps & \\
\hline $1-10 \mathrm{ps}$ & Fast non-radiative processes \\
$1-10 \mathrm{ps}$ & Fast photochemical processes \\
$1.8 \mathrm{ps}(\mathrm{Cu})$ & Laser recovery data [84] \\
$1-10 \mathrm{ps}$ & Characteristic time [85] \\
$4.3 \mathrm{ps}(\mathrm{Cu})$ & Characteristic time [80] \\
$10 \mathrm{ps}$ & Characteristic time [86] \\
\hline
\end{tabular}

One study has looked at the electron-ion interaction in the cooling phase of $500 \mathrm{eV}$ cascades in $\mathrm{Cu}$ and $\mathrm{Ni}$, coupling heat-transfer equations to the simulation [80]. This did not consider energy transfer to electrons from the PKA, but did allow the characteristics of the transfer of energy from the ions to the electrons to be studied. The main effect observed was a reduction in defect production through a damping of ionic motion, in line with earlier studies [81].

There are implicit fast and slow timescales in these processes of materials modification. Once energy has been transferred to a target atom, bonds can be broken in times of the order of femtoseconds. On this timescale, atoms are frozen in the positions to which thermal vibration has carried them. In semiconductors, the timescale for changes due to electronphonon coupling is at least of the order of the vibrational period (typically $0.1-1 \mathrm{ps}$ ), and cooling of carriers to the lattice temperature can take much longer in certain circumstances. An electron temperature will be established after a time determined either by the plasmon frequency or by the electron-electron collision time [82]. For quantum wells, thermalization is seen in 30-200 fs depending on the carrier density [83]. Another group of times characterize somewhat slower processes: allowed optical transitions (1-1000 ns, typically $10 \mathrm{~ns})$, typical spin-forbidden optical transitions (1 ms) and diffusion-controlled processes (1 $\mathrm{s}$ to geological times). One should recognize that some processes on the femtosecond $\left(10^{-15} \mathrm{~s}\right)$ timescale can influence what happens on the engineering timescales (30 years, or $10^{9} \mathrm{~s}$ ) or even geological timescales.

The fast timescales are important; see table 4. Radiation damage leads to highly nonequilibrium situations, often with large amounts of energy associated with small regions of a solid. Kinetic energies of atoms and of electrons in such regions can be large, with individual particles having energies of several electron-volts being common. These regions can have a net charge, since electrons will be scattered out of the central zone, and will return only after some delay. Standard statistical equilibrium expressions will not apply; in particular, there need not be a usefully defined Fermi level in the non-equilibrium condition. It is to be expected that the condition will depend on just how excitation has occurred. Some of the common terms, 


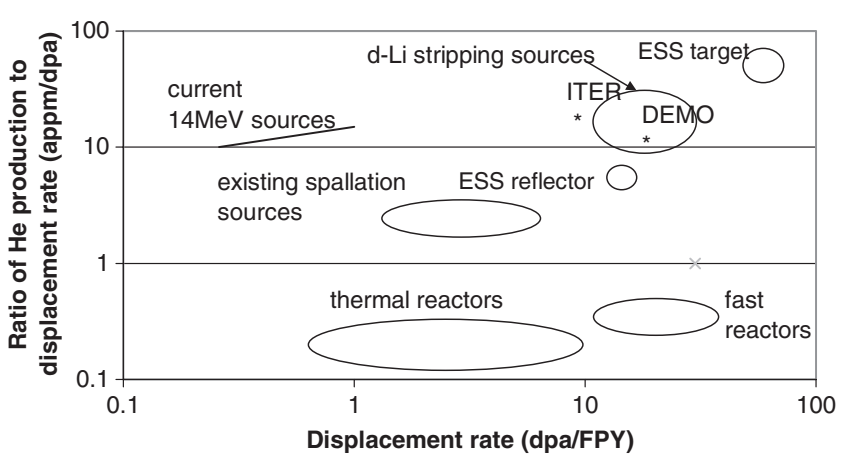

Figure 3. Range of displacement rates and helium production rates for various neutron irradiation situations.

like 'thermal spike' or 'hot spot', suggest that some sort of temperature can be defined. There is no assurance that a single temperature can be identified. Even if the region of space is well defined, equilibration among particles of similar masses (like the electrons alone, or the nuclei alone) can happen much faster than the equalization of any electron temperature with a corresponding lattice temperature. This identifies an important distinction between modes of excitation, namely whether the energy is given initially to the electrons or to the nuclei. Locally, the electrons will be far from equilibrium, and the interatomic potentials normally used to describe adiabatic energy surfaces will be inappropriate in that region. Further, that energy used to excite electrons (so nuclear energy becomes electronic energy) can act as an energy reservoir and also as a means to transfer energy. Both phenomena affect defect recovery in radiation damage.

\section{Evaluation of materials}

The considerations in the previous section on the effects of high-energy neutrons and the resulting high-energy recoils highlight the need for suitable experimental testing of materials before commitment to engineering designs. In the not too recent past the emphasis has been on providing experimental facilities that give sufficiently high displace damage rates and at the same time generating appropriate levels of helium and hydrogen by transmutation. Figure 3 shows the ranges of these parameters for various types of test facility. Let us look in a little more detail at what is available.

\section{Materials testing and mixed spectrum reactors}

These have three main limitations: damage is produced mainly by recoils under $100 \mathrm{keV}$; damage rates are an order of magnitude too small; and gas production rates are a factor of 50 too low (the gas production rates in this case are very dependent on the materials used because of lower energy $[\mathrm{n}, \alpha]$ reactions and the neutron spectrum of the reactor).

\section{Fast reactors (such as Phénix or EBR-2)}

For these, most of the damage is from recoils with energies less than $200 \mathrm{keV}$ (the peak is around $50 \mathrm{keV}$, and the displacement rate is an order magnitude less than the fusion case); their gas production rates are similar to those in materials testing reactors.

\section{Accelerator D-T reaction sources}

Such a source is the RTNS-II facility at Lawrence Livermore Laboratory, which uses a $400 \mathrm{keV}$ deuteron accelerator with a rotating solid state titanium tritide target [87]. This facility has a 
maximum flux of just $1.2 \times 10^{17} \mathrm{~nm}^{-2} \mathrm{~s}^{-1}$ over a small volume, limited by the $10 \mathrm{~mm} \mathrm{spot}$ size of the source. Despite this volume limitation, the source has been useful for basic studies of the effects of $14 \mathrm{MeV}$ neutrons. Difficulties arising from the implantation of deuterium, which limits the life of the source, and problems of stability make further development of this technology unlikely.

\section{Stripping sources (such as the proposed IFMIF)}

One of the most promising approaches to providing a neutron source for fusion materials research exploits the deuteron stripping reaction, a process that involves the breakup of deuterons in the Coulomb field of another nucleus. A beam of energetic deuterons can therefore produce a beam of energetic neutrons when the proton is stripped from the deuteron. If the target nucleus is lithium or beryllium then $(\mathrm{d}, \mathrm{n})$ reactions can also occur, enhancing the production of neutrons. The neutrons can be matched to fusion conditions in terms of recoil spectrum, displacement and gas production rates, but only in a limited volume-the IFMIF facility would have an experimental volume of about $500 \mathrm{~cm}^{3}$ [88]. Maximum neutron and PKA energies are about twice those for the fusion case. Such sources are generally recognized as the best alternative to a fusion neutron source.

\section{Spallation sources}

High-energy proton reactions with heavy target atoms can generate neutrons by two main types of reaction:

(i) Ballistic projection of protons and neutrons arising from the creation of a high-energy particle cascade within the nucleus. This is an immediate process, and the nucleus is left in an excited state. Other light particles may also be knocked out - the hadronic cascade. The secondary particles may induce other spallation interactions. The ballistic neutrons are emitted with a strong angular dependence along the ballistic axis, and have an energy spectrum that extends up to the energy of the incident proton typically $500 \mathrm{MeV}-1 \mathrm{GeV}$.

(ii) The excited nucleus loses neutrons by a process of evaporation. The evaporation neutrons are emitted isotropically with an energy peak typically around $1 \mathrm{MeV}$.

Current spallation sources produce primarily evaporation neutrons, with energies not too dissimilar from the fast fission spectrum. Data from the proposed European Spallation Source (ESS) Project [89] indicate that the contribution from neutrons in the energy range $10 \mathrm{MeV}-$ $1 \mathrm{GeV}$ is much greater. This means that both displacement rates and gas generation rates can be met in a small test facility in the target area. However, a significant proportion of the neutrons is very much more energetic than in the fusion environment. Further, the ESS is a pulsed source, and the effect of this has yet to be resolved. Some spallation sources are continuous. For a deeper discussion of spallation sources for fusion materials testing see [90].

\section{Ion irradiations}

These would require mixed self-ion and gas ion beams, and can only irradiate a small foil sample. Single heavy ion beams would only be useful for research into mechanisms, for example to separate gas effects using a $500 \mathrm{keV}$ self-ion source. Light ion beams, e.g. $20 \mathrm{MeV}$ proton beams, can also allow certain aspects of radiation damage to be studied in small sample.

Stripping sources come closest to fusion conditions, but it is possible that a large spallation source like ESS could provide an accelerated irradiation facility in a small but useful target volume (about 0.41 ). The size of the usable irradiation position is limited by the rapid fall-off 


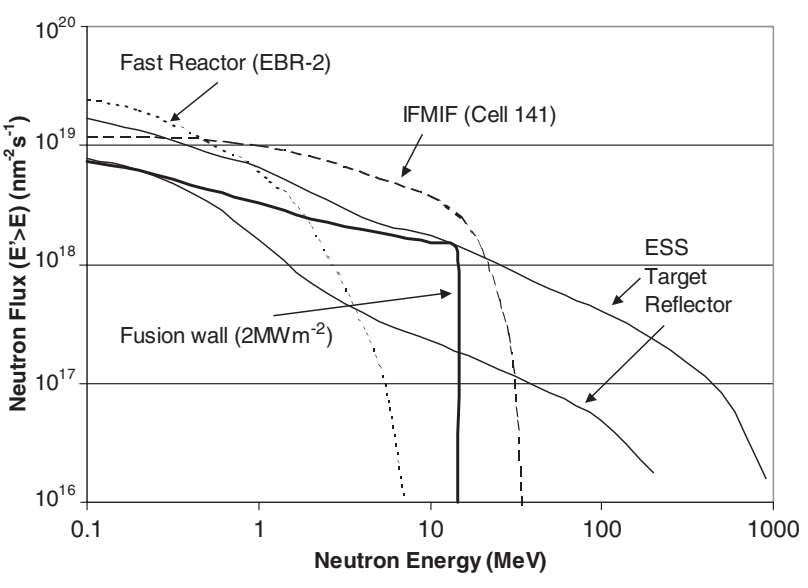

Figure 4. Neutron flux spectra for a range of radiation sources (after [3] and [4]).

of the high-energy component of the neutron spectrum away from the beam axis. Along the beam axis, there will also be high-energy protons that will complicate the conditions. It may be that smaller spallation sources could already provide useful irradiation facilities, and might even be closer to the fusion dose and gas production rates. One question that must be asked is whether such spallation irradiations are useful to the fusion materials programme.

Figure 4 compares the neutron spectra for fast fission, spallation (ESS) and IFMIF with the expected spectrum in the wall of a fusion reactor $[88,89]$. Close analysis of these spectra show that, for the fusion and IFMIF cases, the recoils that produce displacement damage peak at around $500 \mathrm{keV}$ (for Fe). The IFMIF recoil energy distribution is a little broader than the true fusion case, and there are few recoils with energies up to $2 \mathrm{MeV}$-fusion recoils are cut off at just below $1 \mathrm{MeV}$ (for Fe). The spallation case has a peak in recoil energy of a little over $50 \mathrm{keV}$, but the spectrum has a tail that extends up to $70 \mathrm{MeV}$. In terms of the overall energy of the recoil spectrum, this tail is very significant and will create electronic effects that will not be typical of the fusion case.

The IFMIF, when built, will be a very valuable facility for confirming the performance of materials, but the small test volumes will rule out full-scale testing of engineering components. ITER will provide testing of surface heat and particle fluxes but, because of its mode of operation, will only provide limited neutron irradiation testing. Prior to the construction of a large fusion power plant, it will probably be necessary to construct fusion-driven materials testing facilities. There are two main candidates for such a facility.

\section{Gas dynamic trap}

The gas dynamic trap neutron source (GDT-NS) is a proposed mirror linear plasma device, relying on intense neutral beam injection to produce a cylindrical $(12.5 \mathrm{~cm}$ diameter) neutron source region [91]. The concept requires experimental development to confirm its presently predicted performance, and would be more attractive if it were further developed to improve its power density and hence its neutron flux level. The tritium consumption and the overall cost of the device are both modest. About 121 of experimental volume would be available, with damages rates close to those of a fusion power plant.

\section{Spherical tokamak}

The spherical tokamak has the potential to produce a large-volume neutron source for testing power plant components in real time [92], and has the further advantage in its potential for 
application as a power plant. In the neutron source application, it would depend on a high level of neutral beam drive. It is vital to develop a small concept in order to limit the tritium consumption to match the available external supply, and this has largely been achieved on the basis of calculated performance predictions. Like the gas dynamic trap concept, it would enable testing at close to fusion power plant neutron conditions, but would additionally enable testing of plasma facing components and the blanket.

\section{Conclusions}

The fusion materials challenges are of several types. First, there are specifically materials challenges. These are determined in part by the variety of exceptional demands for radiation resistance and for survival under thermal shock, and in part by special demands associated with tritium and with the avoidance of contamination of the plasma. The inhomogeneity of radiation, mechanical and thermal conditions make it natural for most leading materials concepts to involve a controlled mesostructure of some sort, and this increases complexity. For structural materials, as noted above, there are opportunities for novel designs that might reduce specific performance measures, for example, on toughness.

Secondly, there are fundamental condensed matter issues. The primary collision processes will both give momentum to ions and excite electrons. There will be highly non-equilibrium behaviour, in which one major problem will be that the electrons play roles that cannot be represented simply by interatomic potentials. This issue is not a question of devising better interatomic potentials: it is essential to go beyond the standard ideas of a single energy surface defined through such potentials. Some of the key radiation damage processes are hierarchical, i.e., events at an early stage affect events at a later stage in a complex way. To a degree, these can be separated into fast events (from femtoseconds to microseconds) and slow events (seconds to years).

Thirdly, it is not clear that all the key processes at the plasma-solid interface are recognized. There have been serious studies of the plasma side [93] with an idealized description of the solid state, but less substantial treatments of the solid and its interactions with the plasma and radiation fields. The prediction of ablation and spalling as part of conventional materials science is already difficult. It is still harder when a plasma and $14 \mathrm{MeV}$ neutrons both interact with a microstructured inhomogeneous surface.

There are three main avenues proposed in this work for designing materials for fusion power plant: new carbon-based materials as coatings, tailored alloys, and innovative composites designed to separate functionality through its components.

(a) Carbon coatings with mixtures of $\mathrm{sp}^{3}$ and $\mathrm{sp}^{2}$ bonding have good and controllable thermal and mechanical properties. They are likely to have resistance to radiation damage and physical erosion, but this needs to be investigated experimentally in fusion reactor conditions. Carbon is plasma compatible. The main opportunity is to be able to tailor properties to allow viscous relaxation to take place. Tritium retention might be a problem, but this needs to be assessed experimentally. The other design problem stems from changing properties during service, these changes being likely to take the material away from its optimum form. All materials subjected to the extreme fusion reactor environment suffer some form of degradation.

(b) Tailored alloys, based on low activation elements, could minimize the effects of radiation-induced dimensional changes by incorporating fine microstructures stable against displacement damage and thermal processes. This can only be done by using a stable (and hence inert) second phase dispersed on a scale of the order of $10-100 \mathrm{~nm}$. There 
are also strong advantages in creep resistance. Radiation embrittlement is unavoidable, and has to be accounted for in the design and maintenance procedures; in the fusion environment these are likely to be less of a problem than dimensional changes. ODS ferritic/martensitic steels, vanadium alloys and copper alloys could provide the basis for future fusion structural components, but there should be a search for other ways of incorporating a stable nano-scale microstructure.

(c) The problems with plasma-facing and plasma-contacting components cannot be handled by simple materials. Innovative composites seem to provide the only possible solutions. Separating functionality between elements of a composite structure can be done on both a macroscale and a microscale. Erosion and sputtering at the surface, minimizing tritium retention, structural support, heat dissipation and conductance can all be handled by different components. Containing coolant channels poses separate problems that can be tackled using multi-layers. At the microscale laminar structures can reduce thermal loading and radiation damage effects, but the layers need to be between 10 and $100 \mathrm{~nm}$ thick to be effective for the latter case. The use of liquids and unconventional fibre structures could have advantages both at the surface and in separating layers in composites. The overall supporting structure could be a kinematic stacked structure with largely compressive loads.

Finally we should emphasize the current lack of a facility for testing materials in relevant neutron irradiation environment. Whilst it is clear that information collected using fast neutrons, or using tailored neutron spectra from fission or spallation sources, may provide valuable information on damage processes, such information will not confirm the performance of materials irradiated by $14 \mathrm{MeV}$ neutrons. The construction of the IFMIF is an essential part of the fast track option, as it is the only credible solution in the short term. However, the experimental volumes are small, and before commitment to large scale power plant is made it will probably be necessary to construct materials testing fusion reactors based on gas dynamic trap neutron source or spherical tokamak concepts.

\section{Acknowledgments}

Michael Norgett made seminal contributions to the related area of radiation damage for fission reactors, including the widely-used Norgett Robinson Torrens (NRT) model. This paper was written as part of a journal special issue in memoriam Michael Norgett, and begins to identify the work that is needed to set fusion radiation damage studies on the same firm footing as the NRT model did for fission.

This work was performed under UKAEA Fusion Contract QS02646. The authors are grateful for discussions with and support from a number of people active in this field, and particularly Dr Ian Cook and Dr Sergei Dudarev of UKAEA Fusion.

\section{References}

[1] Fowler T K 1999 Rev. Mod. Phys. 71 S456

[2] Robinson D C 1999 Phil. Trans. R. Soc. A 357515

[3] Norgett M J, Robinson M T and Torrens M I 1975 Nucl. Eng. Des. 33457

[4] Chadderton L T and Torrens I McC 1969 Fission Damage in Crystals (London: Methuen)

[5] Dudarev S L and Matthews J R 2002 Nucl. Instrum. Methods Phys. Res. B 193253

[6] Dammak H, Lesueur D, Dunlop A, Legrand P and Morrillo J 1993 Radiat. Eff. Defects Solids 126111

[7] Dunlop A and Lesueur D 1993 Radiat. Eff. Defects Solids 126123

[8] Ioki K et al 1998 J. Nucl. Mater. 258-263 74 
[9] Solonin M I 1998 J. Nucl. Mater. 258-263 30

[10] Barabash V et al 1998 J. Nucl. Mater. 258-263 149

[11] Fenici P et al 1998 J. Nucl. Mater. 258-263 215

[12] Ehrlich K 1999 Phil. Trans. R. Soc. A 357595

[13] Marbach G, Cook I and Maisonnier D 2002 Fusion Eng. Des. 63/64

[14] Airaghi A, Berry J, Condé H, Matos Ferreira C, Newi G, Rebut P-H and Stoneham A M 2000 Five-Year Assessment related to the Specific Programme on Nuclear Fusion: Final Report (European Union, June 2000) pp 1-73 http://www.cordis.lu.fp5/5yr_reports.htm

[15] Philipps V, Roth J and Loarte A 2003 Plasma Phys. Control. Fusion 45 (Suppl. 12A) F17

[16] Kaita R et al 2003 Liquid Li limiter effects on Tokomak plasmas and plasma-liquid surface interactions Princeton Plasma Physics Laboratory Report PPPL-3755

Also Majeski R et al 2004 Testing of liquid limiters in CDX-U PPPL preprint unpublished

[17] Winter J and Gebauer G 1999 J. Nucl. Mater. 266-269 229

[18] Roth J, Plank H and Scwoere R 1996 Phys. Scr. T 6467

[19] Stoneham A M, Godwin P D, Sutton A P and Bull S J 1998 Appl. Phys. Lett. 723142

[20] Prelas M A et al 1993 Laser Part. Beams 1165

[21] Banhart F 1999 Rep. Prog. Phys. 621181

[22] Blank V D et al 1998 JETP 87741

[23] Blank V D et al 1997 J. Mater. Res. 123109

[24] Baker R T K and Harris P S 1978 Carbon 1483

[25] Godwin P D, Horsfield A P, Stoneham A M, Bull S J, Ford I J, Harker A H, Pettifor D G and Sutton A P 1996 Phys. Rev. B 5415785

[26] Convertino A, Visconti P and Cingolani R 2000 J. Vac. Sci. Technol. A 18356

[27] Stoneham A M 1994 Nucl. Instrum. Methods Phys. Res. A 91 1-11

[28] Salonen E, Nordlund K, Tarus J, Ahlegren T, Keinonen J and Wu C H 1999 Phys. Rev. B 6014005

[29] Evans T 1979 The Properties of Diamond ed J E Field (New York: Academic) p 408

[30] Field J E and Pickles C S J 1996 Diamond Relat. Mater. 5625

[31] Prawer S et al 1996 Diamond Relat. Mater. 5405

[32] Davinas J 1993 Solid State Phenom. 30/31 317

[33] Venkatesan T, Calcagno L, Elman B S and Foti G 1987 Ion Beam Modification of Materials vol 2, ed P Mazzoldi and G W Arnold (Amsterdam: Elsevier)

[34] Toulemonde M and Studer F 1993 Solid State Phenom. 30/31 477

[35] Phillips D C, Hitchon J W, Johnson D I and Matthews J R 1984 J. Nucl. Mater. 125202

[36] Gokan H, Esho S and Ohnishi Y 1983 J. Electrochem. Soc. 130143

[37] Kushita K N et al 1999 J. Nucl. Mater. 191346

[38] Zwanger M and Banhart F 1995 Phil. Mag. B 72149

[39] Blank V D et al 1999 Diamond Relat. Mater. 81285

[40] Chou N, Marwick A D, Goldblatt R D, Li L, Coleman G, Heidenreich J E and Paraszczak J R 1992 J. Vac. Sci. Technol. A 10248

[41] Krajnovich D J and Vaquez J E 1993 J. Appl. Phys. 733001

[42] Dartyge E and Sigmund P 1985 Phys. Rev. B 325429

[43] Kuppers J 1995 Surf. Sci. Rep. 22251

[44] Konyashin I, Khvostov V, Babaev V, Guseva M, Bill J and Aldinger F 1999 Diamond Relat. Mater. 82053

[45] Wilson K L et al 1991 Nucl. Fusion 131

[46] Kaukonen M and Nieminen R 2000 Phys. Rev. B 612806

[47] Robertson J 1992 Phys. Rev. Lett. 68220

[48] Chhowalla M, Ferrari A C, Robertson J and Amaratunga G A J 2000 Appl. Phys. Lett. 761419

[49] Garner F A, Toloczko M B and Sencer B H 2000 J. Nucl. Mater. 276123

[50] Rigollet C, Gentzbittel J M and Robert G 1993 J. Physique C 3747

[51] Kohyama A et al 1996 J. Nucl. Mater. 233-237 138

[52] Hishinuma A et al 1998 J. Nucl. Mater. 258-263 193

[53] Little E A 1993 J. Nucl. Mater. 206324

[54] Wilson A M, Clayden M C and Standring J 1987 Evaluation of potential fast reactor cladding alloys by stress ramp testing and predictions of endurance Proc. Conf. on Materials for Nuclear Reactor Core Applications (BNES, Bristol, Oct. 1987) vol 2 (London: British Nuclear Energy Society) p 25

[55] Mukhopadhyay D K, Froes D K and Gelles D S 1998 J. Nucl. Mater. 2631209

[56] Kohyama A et al 1994 J. Nucl. Mater. 215684

[57] Little E A, Mazey D J and Hanks W 1991 Scr. Metall. 251115 
[58] Nakajima K, Shibayama T and Kayano H 1995 J. At. Energy Soc. Japan 37338

[59] Fabritsiev S A et al 1998 J. Nucl. Mater. 2631015

[60] Fabritsiev S A, Zinkle S J and Singh B N 1996 J. Nucl. Mater. 233-237 127

[61] Anzel I, Kneissel A C and Kosec L 1999 Z. Metallk. 90621

[62] Beden I, Brown S G R, Evans R W and Wiltshire B 1987 Res Mech. 2245

[63] Pantyrnyi V 2002 IEEE Trans. Appl. Supercond. 121189

[64] Pantyrnyi V 2003 Bochvar Institute of Inorganic Materials, Moscow (private communication to J R Matthews)

[65] Klueh R L and Bloom E E 1985 The development of austenitic steels for fast induced-radioactivity decay for fusion reactor applications Optimizing Materials for Nuclear Reactors (Proc. Winter Mtg of the Metallurgical Society 1984) ed F A Garner, D S Gelles and F W Witten (Warrendale, PA: The Metallurgical Society) p 73

[66] Garner F A and Brager H R 1985 Dependence of neutron-induced swelling on composition in iron-based austenitic alloys Optimizing Materials for Nuclear Reactors (Proc. Winter Mtg of the Metallurgical Society 1984) ed F A Garner, D S Gelles and F W Witten (Warrendale, PA: The Metallurgical Society) p 87

[67] Kelly A 1999 in discussion of Ehrlich see [12]

[68] Kelly A, Waterman N A and Furness J A G 1997 Proc. 2nd IEA/JUPITER Joint Int. Workshop on SiC/SiC Composites for Fusion Applications (Sendai, Japan: Japanese Society of Materials for Advanced Energy Systems) p 106

[69] Shingu P H et al 1999 Radiat. Eff. Defects Solids 148555

[70] Bolt H et al 1996 J. Nucl. Mater. 237809

[71] Ivanov L I et al 1999 J. Nucl. Mater. 272405

[72] Moir R W et al 1994 Fusion Technol. 255

[73] Kinchin G H and Pease R S 1955 Rep. Prog. Phys. 181

[74] Huang H and Ghoniem N 1993 J. Nucl. Mater. 199221

[75] Itoh N and Stoneham A M 2001 Materials Modification by Electronic Excitation (Cambridge: Cambridge University Press)

[76] Brinkman J A 1954 J. Appl. Phys. 2596

[77] Bacon D J, Gao F and Osetsky Yu N 1999 Nucl. Instrum. Methods Phys. Res. B 15387

[78] Singh B N and Woo C H 1991 Collision cascades and defect accumulation during irradiation Symp. on Materials Modelling: From Theory to Technology (Oxford: Institute of Physics Publishing) pp 117-22

[79] Nguyen-Manh D, Pettifor D G, Cockayne D J H, Mrovec M, Znam S and Vitek V 2003 Bull. Mater. Sci. 2643

[80] Finnis M W, Agnew P and Foreman A J E 1991 Phys. Rev. B 44567

[81] Stoneham A M 1989 Nucl. Instrum. Methods Phys. Res. B 48389 Stoneham A M 1996 Radiat. Eff. 142191

[82] Bochove E J and Walkup J F 1990 Am. J. Phys. 58131

[83] Ryan J F 1998 Hot Electrons in Semiconductors ed N Balkan (Oxford: Oxford University Press) chapter 8

[84] Govolov V V, Matveets Yu A, Sanov A M and Letokhov V S 1992 JETP Lett. 55440

[85] Sigmund P 1974 Appl. Phys. Lett. 25169 Sigmund P 1975 Appl. Phys. Lett. 2752 (erratum)

[86] Landau L D 1936 Z. Phys. Sowjetunion 10154

See also, Landau L D and Lifshitz E M 1972 Course of Theoretical Physics: Physical Kinetics (Oxford: Pergamon)

[87] Booth R et al 1977 Nucl. Instrum. Methods 14525

[88] Möslang A (ed) 1999 IFMIF conceptual design evaluation report FZKA Report 6199

[89] Ullmaier H, Fliges D and Bauer G 2001 Information form ESS project at FZ Juelich presented at a colloquium at the Max Planck Institute for Plasma Physics, Garching

[90] Cottrell G A and Baker L J 2003 J. Nucl. Mater. 318260

[91] Fischer U, Möslang A and Ivanov A A 2000 Fusion Eng. Des. 48307

[92] Hender T C, Voss G M and Taylor N P 1999 Fusion Eng. Des. 45265

[93] Counsell G F et al 2001 J. Nucl. Mater. 290255 